\title{
Quality of Life of Children with Chronic Kidney Disease Undergoing Renal Replacement Therapy
}

\section{Morales $\mathbf{P}^{1^{*}}$, Loza $\mathbf{R}^{2}$, Vasquez $\mathbf{J}^{1}$, Baique $\mathbf{P}^{3}$ and Reyes $\mathbf{M}^{3}$}

${ }^{1}$ Cardiopediatry Department, National Cardiovascular Institute Alberto Peschiera Carrillo, Peru

${ }^{2}$ Peritoneal Dialysis Unit, Pediatric Department, Cayetano Heredia Hospital, Peruvian University Cayetano Heredia, Peru

${ }^{3}$ Department of Pediatrics, National Hospital Edgardo Rebagliati Martins, Peru

*Corresponding author: Percy Antonio Morales Yampufé, Pediatric Intensivist, Md. Pediatric Intensive Care Unit, Cardiopediatry Department, National Cardiovascular Institute Alberto Peschiera Carrillo, Peru. Tel: +51955956764; E-mail: percy.morales.y@upch.pe

Received Date: September 15, 2018; Accepted Date: October 09, 2018; Published Date: October 19, 2018

Copyright: $\odot 2018$ Morales $\mathrm{P}$, et al. This is an open-access article distributed under the terms of the Creative Commons Attribution License, which permits unrestricted use, distribution, and reproduction in any medium, provided the original author and source are credited.

\begin{abstract}
Introduction: End-Stage Renal Disease (ESRD) is a major health problem. The Health-related Quality of Life (HRQOL) of children with end-stage renal disease influences their future life in terms of autonomy, psychosexual development, and social integration.
\end{abstract}

Objective: To evaluate the HRQOL of children with ESRD according to the modality of renal replacement therapy: Hemodialysis (HD), Peritoneal Dialysis (PD), and Renal Transplant (RT).

Population and Methods: Cross-sectional, observational, prospective study that included 79 children between 5 and 17 years of age (mean of $13.3 \pm 3.4$ ) diagnosed with End-Stage Renal Disease (with renal replacement therapy). The applied questionnaire was KINDL®.

Results: Of the 79 children and adolescents with ESRD, 39 (49.4\%) had PD, 21 (26.6\%) had HD, and 19 (24.1\%) had RT. The total HRQOL for the children with PD was $60.39 \pm 7.88 ; 62 \pm 9.71$ for HD, and $83.44 \pm 9.68$ for RT.

Conclusion: The patients who underwent RT had higher HRQOL scores compared to their PD and HD peers both in terms of the total score and in all dimensions, while the scores did not differ for the patients on dialysis.

Keywords: Quality of life; Chronic kidney disease; Renal replacement therapy; Child; Adolescent

\section{Introduction}

End-Stage Renal Disease (ESRD) is a major health problem with an annual rate of occurrence of approximately 5 to 10 children per million [1]. In Guatemala, the prevalence of ESRD in children has been reported to be 4.9 patients per million [2]. This disease is a condition that requires special care such as a strict diet, change of lifestyle, and frequent medical monitoring, and it is associated with complications including anemia, cardiovascular diseases, lung pathologies, the development of neurological disorders, and psychosocial problems [3]. The various options at present for renal replacement therapy in children with ESRD are: Hemodialysis (HD), Peritoneal Dialysis (PD), and Renal Transplant (RT). There has been a consequent increase in life expectancy, and as a result, it is likely that more children with ESRD will reach adult age [4]. The WHO considers Health-related Quality of Life (HRQOL) as the "perception of the individual to their position in life in the context of the culture and value system in which they live and in relation to their objectives, expectations, standards, and concerns". In general, we can consider this to be a subjective and multidimensional concept [5]. Of the total research to date on HRQOL, only $13 \%$ relates to childhood and adolescence, and even then, most is dedicated to oncology and transplantation while the HRQOL research regarding chronic diseases amounts to a much smaller proportion [6]. The instruments to measure HRQOL in patients comprise: Chip (Child Health and Illness Profile), PedsQL (Pediatric Quality of Life), KINDL (from German "Kinder Lebensqualitatsfragebogen", which means quality of life in children) among others; all evaluated the HRQOL taking into account dimensions related to physical, psychological, and social development [7]. It is important to know the HRQOL of children with ESRD since it directly influences their future lives in terms of aspects such as autonomy, psychosexual development, and social integration. A study that compared healthy young adults with those who grew up with a chronic disease or who underwent a chronic treatment that started in childhood has highlighted the impact of the disease and/or treatment on development [8].

The objective of the present work was to evaluate the quality of life of children with terminal chronic renal disease according to the modality of the renal replacement therapy.

\section{Population and Methods}

\section{Design of the study}

This was a descriptive, cross-sectional, prospective, observational study of patients diagnosed with ESRD who underwent renal replacement therapy at the Pediatric Nephrology unit of the Cayetano Heredia National Hospital (CHNH) in Lima, Peru. 


\section{Population}

All of the patients were between 5 and 17 years of age, had a diagnosis of terminal chronic renal disease, and they underwent renal replacement therapy.

\section{Inclusion criteria}

- Diagnosis of ESRD corroborated in the registry of patients undergoing renal replacement therapy at the $\mathrm{CHNH}$.

- Renal replacement therapy (HD, PD, or RT) at the start of the investigation for at least three months.

- Attending a minimum of three check-ups per year.

- In the 5 to 17 years of age group.

- Provided informed acceptance and the parents or guardians provided their written informed consent.

\section{Exclusion criteria:}

- In replacement therapy (HD, PD, or $\mathrm{RT}$ ) at the start of the investigation, for a period of less than three months.

- Patients and parents or guardians refused to participate in the study.

- Patients with an intellectual disability.

- Patient receiving replacement therapy in an irregular manner (e.g. failure to attend a hemodialysis session or the follow-up on an outpatient basis in the case of PD or RT).

\section{Sample}

The type of sampling was non-probabilistic of the type by convenience.

\section{Procedures and techniques}

These were in regard to patients with ESRD in renal replacement therapy during the follow-up at an outpatient clinic for cases of peritoneal dialysis and renal transplantation, and for cases of hemodialysis before or after their treatment. The children and their parents were asked to provide their acceptance ( 7 years of age onwards) and consent, respectively, for participation in the study. This acceptance was registered by the completion and signing of an assent/ informed consent form.

\section{Data collection instrument}

This was based on the data collection sheet for the study. To assess the quality of life of patients with ESRD we interviewed the children using the $\mathrm{KINDL}^{\oplus}$ questionnaire. This questionnaire contains 24 questions (the Kiddy-KINDL version has 12 questions) that cover six dimensions: physical, emotional well-being, self-esteem, family, friends, and school. There were different versions of the questionnaire for each age group: Kiddy-KINDL for children 4 to 7 years of age, Kid-KINDL for 8 to 12 years of age, and Kiddo-KINDL for 13 to 17 years of age. The responses to the KINDL questionnaire are based on a Likert scale comprising five categories, except the Kiddy version, which has three categories of responses. The questions refer to the week prior to the interview and the scores obtained from the average of each dimension are transformed to a scale from 0 to 100 , where a higher score represents a better HRQOL. It is possible to obtain a single total score or a global index of HRQOL from the average of the six dimensions [9].

\section{Statistical analysis}

The information was processed using SPSS version 22.0 for Windows software. The descriptive statistics are presented as tables of frequencies, means, standard deviations, and confidence intervals. Application of the Shapiro-Wilk test showed that the HRQOL values did not have a normal distribution. We used the Kruskal-Wallis nonparametric test to determine whether the averages were independent of the three renal replacement therapies. This procedure was performed for each dimension and for the total HRQOL score.

\section{Results}

This study comprised 79 patients diagnosed with ESRD who underwent renal replacement therapy at the indicated pediatric nephrology unit. The distribution of the treatments was as follows: PD for 39 patients (49.4\%), HD for 21 patients (26.6\%), and RT for 19 patients $(24.1 \%)$ carried out between July and September 2014. The patients were between 5 and 17 years of age (with a mean of $13.3 \pm$ 3.4).

\section{Peritoneal dialysis}

There were 39 patients (19 males and 20 females) who, on average, were $12.54 \pm 3.5$ years of age and who, on average, had undergone 2.18 \pm 1.11 years of therapy. The most frequent complication was arterial hypertension (occurring in 79.5 percent). On average, they had $1.67 \pm$ 0.9 siblings and 87.2 percent attended a public school (Table 1 ).

\begin{tabular}{|c|c|c|c|c|c|c|c|c|c|c|c|c|}
\hline \multirow{2}{*}{ Features } & \multicolumn{4}{|c|}{$\begin{array}{c}\text { Peritoneal Dialysis } \\
\mathrm{N}=39(49.4 \%)\end{array}$} & \multicolumn{4}{|c|}{$\begin{array}{l}\text { Hemodialysis } \\
\mathrm{N}=21(26.6 \%)\end{array}$} & \multicolumn{4}{|c|}{$\begin{array}{l}\text { Renal Transplant } \\
\mathrm{N}=19(24.1 \%)\end{array}$} \\
\hline & $\mathbf{N}$ & $\%$ & Mean & SD & $\mathbf{N}$ & $\%$ & Mean & SD & $\mathbf{N}$ & $\%$ & Mean & SD \\
\hline $\begin{array}{l}\text { Age Tot. (5 to } 17 \text { years) } \\
\text { (avg } 13.3 \pm 3.4 \text { ) }\end{array}$ & & & 12.54 & 3.5 & & & 13.19 & 3.78 & & & 15.11 & 1.97 \\
\hline 4-7 years & 5 & 12.8 & & & 1 & 4.8 & & & 0 & 0 & & \\
\hline $8-12$ years & 15 & 38.5 & & & 6 & 28.6 & & & 2 & 10.5 & & \\
\hline $13-18$ years & 19 & 48.7 & & & 14 & 66.7 & & & 17 & 89.5 & & \\
\hline
\end{tabular}


Citation: Morales P, Loza R, Vasquez J, Baique P, Reyes M (2018) Quality of Life of Children with Chronic Kidney Disease Undergoing Renal Replacement Therapy . J Kidney 4: 173. doi:10.4172/2472-1220.1000173

Page 3 of 7

\begin{tabular}{|c|c|c|c|c|c|c|c|c|c|c|c|c|}
\hline \multicolumn{13}{|l|}{ Gender } \\
\hline Male & 19 & 48.7 & & & 10 & 47.6 & & & 10 & 52.6 & & \\
\hline Female & 20 & 51.3 & & & 11 & 52.4 & & & 9 & 47.4 & & \\
\hline \multicolumn{13}{|l|}{ Origin } \\
\hline Lima & 19 & 48.7 & & & 18 & 85.7 & & & 14 & 73.7 & & \\
\hline Province & 20 & 51.3 & & & 3 & 14.3 & & & 5 & 26.3 & & \\
\hline Therapy Duration & & & 2.18 & 1.11 & & & 1.76 & 0.77 & & & 3.32 & 1.46 \\
\hline $1-2$ years & 26 & 66.7 & & & 17 & 81 & & & 5 & 26.3 & & \\
\hline 3-4 years & 12 & 30.6 & & & 4 & 19 & & & 8 & 42.1 & & \\
\hline $5-6$ years & 1 & 2.6 & & & 0 & 0 & & & 6 & 31.6 & & \\
\hline \multicolumn{13}{|l|}{ Complications } \\
\hline Short stature & 28 & 71.8 & & & 16 & 76.2 & & & 12 & 63.2 & & \\
\hline Osteodystrophy & 3 & 7.7 & & & 5 & 23.8 & & & 0 & 0 & & \\
\hline Anemia & 24 & 61.5 & & & 16 & 76.2 & & & 5 & 26.3 & & \\
\hline Health Technology Assessment & 31 & 79.5 & & & 17 & 81 & & & 6 & 31.6 & & \\
\hline Cardiac insufficiency & 2 & 5.1 & & & 2 & 9.5 & & & 0 & 0 & & \\
\hline Number of siblings & & & 1.67 & 0.87 & & & 1.9 & 1.18 & & & 1.74 & 1.41 \\
\hline $0-1$ & 17 & 43.6 & & & 9 & 42.9 & & & 10 & 52.6 & & \\
\hline $2-3$ & 22 & 56.4 & & & 10 & 47.6 & & & 7 & 36.8 & & \\
\hline $4-6$ & 0 & 0 & & & 2 & 9.5 & & & 2 & 10.5 & & \\
\hline \multicolumn{13}{|l|}{ Type of School } \\
\hline Public & 34 & 87.2 & & & 20 & 95.2 & & & 15 & 78.9 & & \\
\hline Private & 3 & 7.7 & & & 0 & 0 & & & 4 & 21.1 & & \\
\hline Did not attend & 2 & 5.1 & & & 1 & 4.8 & & & 0 & 0 & & \\
\hline
\end{tabular}

Table 1: Characteristics of the patients.

The average total HRQOL score was 60.39 , the physical well-being esteem score was 62.50 , the family score was 67.15 , the friends score score was 56.73, the emotional well-being score was 65.22, the self- was 66.67, and the school score was 44.07 (Table 2).

\begin{tabular}{|c|c|c|c|c|c|c|c|c|c|}
\hline \multirow[b]{2}{*}{ Dimension } & \multirow[b]{2}{*}{ Therapy } & \multirow[b]{2}{*}{$\mathbf{N}$} & \multirow[b]{2}{*}{ Mean } & \multirow[b]{2}{*}{ SD } & \multirow[b]{2}{*}{ SEM } & \multicolumn{2}{|c|}{$95 \%$} & \multirow[b]{2}{*}{ Min } & \multirow[b]{2}{*}{$\operatorname{Max}$} \\
\hline & & & & & & $\begin{array}{l}\text { Lower } \\
\text { Limit }\end{array}$ & $\begin{array}{l}\text { Upper } \\
\text { Limit }\end{array}$ & & \\
\hline \multirow{4}{*}{ Physical well-being 100} & PD & 39 & 56.7 & 14.9 & 2.38 & 51.91 & 61.55 & 25 & 81.3 \\
\hline & $\mathrm{HD}$ & 21 & 57.7 & 13.8 & 3.02 & 51.45 & 64.03 & 31.3 & 100 \\
\hline & RT & 19 & 92.4 & 7.68 & 1.76 & 88.73 & 96.13 & 75 & 100 \\
\hline & Total & 79 & 65.6 & 20 & 2.25 & 61.1 & 70.07 & 25 & 100 \\
\hline \multirow{2}{*}{ Emotional wellness 100} & PD & 39 & 65.2 & 14.4 & 2.31 & 60.56 & 69.89 & 31.3 & 100 \\
\hline & $H D$ & 21 & 61.9 & 12.3 & 2.69 & 56.29 & 67.52 & 31.3 & 75 \\
\hline
\end{tabular}


Citation: $\quad$ Morales P, Loza R, Vasquez J, Baique P, Reyes M (2018) Quality of Life of Children with Chronic Kidney Disease Undergoing Renal Replacement Therapy . J Kidney 4: 173. doi:10.4172/2472-1220.1000173

Page 4 of 7

\begin{tabular}{|c|c|c|c|c|c|c|c|c|c|}
\hline & RT & 19 & 86.5 & 12.4 & 2.84 & 80.55 & 92.48 & 56.3 & 100 \\
\hline & Total & 79 & 69.5 & 16.4 & 1.85 & 65.78 & 73.15 & 31.3 & 100 \\
\hline \multirow{4}{*}{ Self-esteem 100} & PD & 39 & 62.5 & 15.8 & 2.54 & 57.37 & 67.63 & 25 & 100 \\
\hline & $\mathrm{HD}$ & 21 & 69.9 & 14.6 & 3.19 & 63.29 & 76.59 & 37.5 & 100 \\
\hline & RT & 19 & 93.8 & 14.4 & 3.31 & 86.79 & 100.7 & 37.5 & 100 \\
\hline & Total & 79 & 72 & 19.7 & 2.21 & 67.59 & 76.4 & 25 & 100 \\
\hline \multirow{4}{*}{ Family 100} & PD & 39 & 67.2 & 10.5 & 1.68 & 63.74 & 70.55 & 50 & 87.5 \\
\hline & $\mathrm{HD}$ & 21 & 68.2 & 15 & 3.28 & 61.31 & 75 & 18.8 & 87.5 \\
\hline & RT & 19 & 80.3 & 21.6 & 4.95 & 69.86 & 90.66 & 18.8 & 100 \\
\hline & Total & 79 & 70.6 & 15.8 & 1.78 & 67.03 & 74.11 & 18.8 & 100 \\
\hline \multirow{4}{*}{ Friends 100} & PD & 39 & 66.7 & 13 & 2.08 & 62.45 & 70.88 & 31.3 & 87.5 \\
\hline & $\mathrm{HD}$ & 21 & 67 & 15.1 & 3.29 & 60.1 & 73.82 & 25 & 100 \\
\hline & RT & 19 & 87.2 & 12.2 & 2.81 & 81.28 & 93.07 & 62.5 & 100 \\
\hline & Total & 79 & 71.7 & 15.9 & 1.79 & 68.12 & 75.23 & 25 & 100 \\
\hline \multirow{4}{*}{ School 100} & PD & 39 & 44.1 & 22.2 & 3.56 & 36.87 & 51.27 & 6.25 & 75 \\
\hline & $\mathrm{HD}$ & 21 & 47.3 & 21 & 4.58 & 37.78 & 56.87 & 6.25 & 75 \\
\hline & RT & 19 & 60.5 & 21.3 & 4.88 & 50.28 & 70.77 & 0 & 100 \\
\hline & Total & 79 & 48.9 & 22.4 & 2.52 & 43.87 & 53.91 & 0 & 100 \\
\hline \multirow{4}{*}{ Quality of life total 100} & PD & 39 & 60.4 & 7.88 & 1.26 & 57.84 & 62.94 & 40.6 & 77.1 \\
\hline & $\mathrm{HD}$ & 21 & 62 & 9.71 & 2.12 & 57.58 & 66.43 & 31.3 & 77.1 \\
\hline & RT & 19 & 83.4 & 9.68 & 2.22 & 78.78 & 88.11 & 55.2 & 97.9 \\
\hline & Total & 79 & 66,36 & 13 & 1.47 & 63.44 & 69.28 & 31.3 & 97.9 \\
\hline
\end{tabular}

Table 2: HRQL scores by size and total according to the replacement therapy.

\section{Hemodialysis}

There were 21 patients ( 10 males and 11 females), with an average of $13.19 \pm 3.78$ years of age and an average of $1.76 \pm 0.77$ years in therapy. The most frequent complication was arterial hypertension (in 81 percent). On average, they had $1.9 \pm 1.18$ siblings and 95.2 percent attended a public school (Table 1). The average total HRQOL score was 62. the physical well-being score was 57.74 , the emotional well-being score was 61.90 , the self-esteem score was 69.94 , the family score was 68.15 , the friends score was 66.67 , and the school score was 47.32 (Table 2).

\section{Renal transplant}

There were 19 patients ( 10 males and 9 females), with an average $15.11 \pm 1.97$ years of age and an average of $3.32 \pm 1.46$ years in therapy.
The most frequent complication was stature (in 63.2 percent). On average, they had $1.74 \pm 1.41$ siblings and 78.9 percent attended a public school (Table 1). The average total HRQOL score was 83.44 , the score for physical well-being was 92.43 , the score for emotional wellbeing was 86.51 , the score for self-esteem was 93.75 , the family score was 80.26 , the score for friends was 87.17 , and the score for school was 60.53 (Table 2). With the exception of anemia $(\mathrm{p}=0.005)$ and arterial hypertension $(\mathrm{p}=0.001)$, the characteristics did not differ significantly between the three renal replacement therapies (Table 1). The KruskalWallis test of the averages of the HRQOL scores for each dimension and for the total score confirmed that the HRQOL scores were not equal for the different renal replacement therapies (Table 3).

\begin{tabular}{|l|l|l|l|}
\hline Dimension & Therapy & N & Range Average \\
\hline Physical well-being $\mathbf{1 0 0}$ & PD & 39 & 31.06 \\
\hline
\end{tabular}


Citation: Morales P, Loza R, Vasquez J, Baique P, Reyes M (2018) Quality of Life of Children with Chronic Kidney Disease Undergoing Renal Replacement Therapy . J Kidney 4: 173. doi:10.4172/2472-1220.1000173

Page 5 of 7

\begin{tabular}{|c|c|c|c|}
\hline & $\mathrm{HD}$ & 21 & 30.83 \\
\hline & RT & 19 & 68.47 \\
\hline & Total & 79 & \\
\hline \multirow{4}{*}{ Emotional wellness 100} & PD & 39 & 34.23 \\
\hline & $H D$ & 21 & 29.86 \\
\hline & RT & 19 & 63.05 \\
\hline & Total & 79 & \\
\hline \multirow{4}{*}{ Self-esteem 100} & PD & 39 & 28.76 \\
\hline & $\mathrm{HD}$ & 21 & 37.64 \\
\hline & RT & 19 & 65.68 \\
\hline & Total & 79 & \\
\hline \multirow{4}{*}{ Family 100} & $\mathrm{PD}$ & 39 & 33.54 \\
\hline & $\mathrm{HD}$ & 21 & 37.64 \\
\hline & RT & 19 & 55.87 \\
\hline & Total & 79 & \\
\hline \multirow{4}{*}{ Friends 100} & PD & 39 & 33.18 \\
\hline & HD & 21 & 33.02 \\
\hline & RT & 19 & 61.71 \\
\hline & Total & 79 & \\
\hline \multirow{4}{*}{ School 100} & $\mathrm{PD}$ & 39 & 35.74 \\
\hline & $\mathrm{HD}$ & 21 & 36.79 \\
\hline & RT & 19 & 52.3 \\
\hline & Total & 79 & \\
\hline \multirow{4}{*}{ Quality of life Total 100} & $\mathrm{PD}$ & 39 & 29.79 \\
\hline & $H D$ & 21 & 34.55 \\
\hline & RT & 19 & 66.97 \\
\hline & Total & 79 & \\
\hline
\end{tabular}

Table 3: Kruskal-Wallis treatment for the averages of the HRQL scores according to the replacement therapy.

\begin{tabular}{|l|l|l|l|l|l|l|l|}
\hline Statistical Test & $\begin{array}{l}\text { Physical well-being } \\
\mathbf{1 0 0}\end{array}$ & $\begin{array}{l}\text { Emotional } \\
\text { wellness } \mathbf{1 0 0}\end{array}$ & $\begin{array}{l}\text { Self-esteem } \\
\mathbf{1 0 0}\end{array}$ & Family $\mathbf{1 0 0}$ & Friends $\mathbf{1 0 0}$ & School $\mathbf{1 0 0}$ & Quality of life Total 100 \\
\hline Chi-square test & 39.08 & 26.35 & 34.04 & 12.65 & 23 & 7.37 \\
\hline GI & 2 & 2 & 2 & 2 & 2 & 2 \\
\hline Asymptotic Sig. & 0 & 0 & 0 & 0 & 0 & 0.03 \\
\hline
\end{tabular}

Table 4: Contrast statistical test of KRUSKAL-WALLIS.

Pairwise analysis of the differences between the averages of HRQOL indicated that the HRQOL scores for RT were higher relative to PD and HD for the total score and for all of the dimensions (Table 4). 


\section{Discussion}

There have been very few studies to date on HRQOL in children and adolescents undergoing renal replacement therapy. Optimal care of children with ESRD is of great interest because it is reflected in the results for HRQOL [10]. From a medical perspective, renal transplantation represents the renal replacement therapy of choice for children [11]. The quality of life of children with ESRD is an important factor for their adult life. Recent studies have recommended that nephrologist pediatricians place more emphasis on the development of social skills and on achieving independence of the children in order to prepare them for active participation in society when they reach adulthood [12]. The present study compared the HRQL in patients treated by Hemodialysis (HD), Peritoneal Dialysis (PD), and Renal Transplantation (RT). For this, we used the KINDL questionnaire, which evaluates the HRQOL in children and adolescents who are healthy or who have chronic diseases, including ESRD. Additionally, variations of this questionnaire were used to account for different age groups.

The studies to date that compared the HRQOL according to the renal replacement therapy have yielded conflicting results. Eijsermans et al. showed that children undergoing HD had a similar HRQOL as their healthy controls [13]. By contrast, Brunelli et al. found that patients on dialysis had worse HRQOL scores than their healthy counterparts [14]. In 2006, Goldstein et al. noted the best HRQOL scores in RT patients compared to patients receiving dialysis (HD or $\mathrm{PD})$. In terms of physical and psychosocial health; no difference was observed between the values of HRQOL when HD and PD were compared [15]. In 2009, Goldstein et al. found that the HRQOL scores for patients undergoing RT were higher than the scores of patients in dialysis, but the differences were not statistically significant, except in the family dimension and interaction with peers [10]. McKenna et al. found that the HRQOL scores for patients undergoing dialysis were higher in all of the dimensions relative to RT patients $[3,16]$. By contrast, Riaño-Galán et al. compared RT and dialysis and they found that the HRQOL scores differed according to the different dimensions. The satisfaction and discomfort dimensions favored RT, while the resilience and risk dimensions favored the dialysis group [17].

In 2010, Buyan et al. noted that RT patients had better HRQOL scores for the physical well-being, self-esteem, and friends dimensions as well as for the total score compared to dialysis patients; but they had similar scores for the perception of illness dimension. Likewise, they noted that patients undergoing $\mathrm{PD}$ had better scores than those undergoing HD in the physical well-being and school dimensions as well as for the total score [12]. Our results show that the RT patients had better scores in all of the dimensions as well as in terms of the total score compared to the group undergoing dialysis (HD and PD), which is in agreement with the studies by Goldstein and Buyan. There are many reasons that can explain these results such as, for example, the fact that this type of patient has a better chance of survival. In our study, they had the lowest number of complications and the lowest incidence of complications such as short stature, which is particularly important for self-esteem. Unlike the above-mentioned studies, RT patients had higher scores than dialysis patients for the emotional wellbeing, family, and school dimensions. This may be because these patients are more secure, have less stress, and better self-satisfaction from an emotional perspective. In terms of family interaction, they felt closer to the group to which they belong, although the average number of siblings did not vary substantially. For the school dimension, the higher scores may be due to better attendance rates and less time spent on renal replacement therapy in comparison to the group on dialysis [10].

The comparison of patients undergoing HD or PD did not reveal any statistically significant differences in terms of their scores for any of the dimensions or the total score. This was also found in the study by Goldstein in 2006, but contrasts with the study of Buyan, in which the group undergoing PD had higher scores than the HD group. An explanation for our results could be that this type of patient tends to exhibit a greater number of complications and a higher number of hospitalizations, and hence, on the whole, they are those that have the greatest number of absences from educational centers. We recognize the limitations of this study, such as the collection of data for patients in different age groups. This can result in different experiences in their relations in the different dimensions, as some may experience the start of their illness at a younger age, which can have a deleterious effect on their perception of their quality of life.

\section{Conclusion}

It was observed that the RT patients had better HRQOL relative to their peers undergoing $\mathrm{PD}$ and HD. This was based on their total HRQOL score and the score for all of the separate dimensions, while there were no differences between the scores of patients on dialysis.

\section{References}

1. McDonald SP, Craig JC, Australian and New Zealand Pediatric Nephrology Association (2004) Long-term survival of children with endstage renal disease. N Engl J Med 350: 2654-2662.

2. Cerón A, Fort MP, Morine CM, Lou-Meda R (2014) Chronic kidney disease among children in Guatemala. Rev Panam Salud Publica 36: 376-382.

3. McKenna AM, Keating LE, Vigneux A, Stevens S (2006) Quality of life in children with chronic kidney disease-patient and caregiver assessments. Nephrol Dial Transplant 21: 1899-1905.

4. Chan JC, Williams DM, Roth KS (2002) Kidney failure in infants and children. Pediatr Rev 23: 47-60.

5. WHO (1995) The World Health Organization Quality of Life Assessment (WHOQOL): Position paper from the World Health Organization. Soc Sci Med 41: 1403-1409.

6. Gaite L (2008) Quality of life related to health in children with chronic disease. Bol Pediatr 48: 337-346.

7. Quiceno JM, Vinaccia S (2013) Health-related quality of life infantile: An approach from chronic illness. Psychol Av Discip 7: 69-86.

8. Stam H, Hartman EE, Deurloo JA, Groothoff J (2006) Young adult patients with a history of pediatric disease: Impact on course of life and transition into adulthood. J Adolesc Health 39: 4-13.

9. Rajmil L, Serra-Sutton V, Fernandez-Lopez JA, Berra S (2004) Spanish version of the German quality of life questionnaire related to health in children and adolescents: The Kindl. An Pediatr 60: 514-521.

10. Goldstein SL, Rosburg NM, Warady BA, Seikaly M, McDonald R, et al. (2009) Pediatric end stage renal disease health-related quality of life differs by modality: A PedsQL ESRD analysis. Pediatr Nephrol 24: 1553-1560.

11. Kabbali N, Mikou S, El Bardai G, Najdi A (2015) Eligibility for renal transplantation: A Moroccan interregional survey. Saudi J Kidney Dis Transpl 26: 153-160.

12. Buyan N, Türkmen MA, Bilge I, Baskin E, Haberal M, et al. (2010) Quality of life in children with chronic kidney disease (with child and parent assessments). Pediatr Nephrol 25: 1487-1496.

13. Eijsermans R, Creemers D, Helders P, Schröder C (2004) Motor performance, exercise tolerance, and health-related quality of life in children on dialysis. Pediatr Nephrol 19: 1262-1266. 
Citation: Morales P, Loza R, Vasquez J, Baique P, Reyes M (2018) Quality of Life of Children with Chronic Kidney Disease Undergoing Renal Replacement Therapy . J Kidney 4: 173. doi:10.4172/2472-1220.1000173

Page 7 of 7

14. Brunelli G, Nogueira P, Pestana J, Diniz D (2012) Quality of life in children on dialysis. Int Urol Nephrol 44: 1515-1519.

15. Goldstein SL, Graham N, Burwinkle T, Warady B, Farrah R, et al. (2006) Health-related quality of life in pediatric patients with ESRD. Pediatr Nephrol 21: 846-850.
16. Shroff R, Ledermann S (2009) Long-term outcome of chronic dialysis in children. Pediatr Nephrol 24: 463-474.

17. Riaño-Galán I, Málaga S, Rajmil L, Ariceta G, Navarro M, et al. (2009) Quality of life of adolescents with end-stage renal disease and kidney transplant. Pediatr Nephrol 24: 1561-1568. 